\title{
Severe Malaria with Acute Kidney Injury and Post-Dialysis Hypocalcaemia and Hypertension: A Case Report of a Young Patient Managed in a Resource Limited Setting
}

\author{
Wafula Innocent, MBChB*
}

Medical Doctor, Kakamega County General Hospital, Kenya

*Corresponding author: Wafula Innocent, MBChB, (University of Nairobi), Medical Doctor, Kakamega County General Hospital, P.O. Box 45-50115, Kakunga, Kenya, Tel: +254719257517

\begin{abstract}
Malaria is a leading cause of paediatric morbidity and mortality in Africa. Plasmodium falciparum species is commonly associated with severe complications of malaria including severe anaemia, prostration, altered consciousness, hypoglycaemia, pulmonary oedema, haemoglobinuria, and acute kidney injury (AKI). In patients with these complications, the cornerstone of treatment is prompt administration of antimalarials and the provision of appropriate supportive care. AKI is an established independent predictor for mortality in children with severe malaria. In patients with malaria-associated AKI, cautious fluid administration and renal replacement therapy could be lifesaving. In this case report, a 12-year-old patient was managed for severe malaria complicated by acute kidney injury (AKI) and post-dialysis hypocalcaemia and hypertension.
\end{abstract}

\section{Introduction}

Despite the unprecedented decline in Plasmodium falciparum transmission in Africa since 2000 [1], severe malaria is still a leading cause of paediatric hospital admissions, morbidity and mortality in sub-Saharan Africa, and in Kenya. According to the World Health Organization (WHO) World Malaria Report (2020) [2], there was an estimated 229 million cases of Malaria globally in 2019, with over 400,000 associated deaths, $94 \%$ of which were recorded in Africa [2]. Although children under 5 years are at a considerable higher risk of malaria-associated morbidity and mortality, older children also suffer from the severe forms of the disease. In Kenya, the Western region is one of the main malaria endemic zones.

Among the parasites of the genus Plasmodium, (P. falciparum, $P$. vivax, $P$. malariae, $P$. ovale, and $P$. knowlesi), $P$. falciparum is the most common species associated with complications such as severe anaemia, prostration, altered consciousness, hypoglycaemia, pulmonary oedema, haemoglobinuria [3], and acute kidney injury [4]. We report a case of an older paediatric patient presenting with severe malaria with acute kidney injury (AKI) and post-dialysis hypocalcemia and hypertension.

\section{Case Report}

A 12-year-old primary school student residing in the malaria endemic Western region of Kenya (Kakamega County) presented with headache, vomiting, fever, arthralgia and lethargy for three days; and altered consciousness, and prostration for a day before hospitalization at Kakamega County General Hospital. Clinical examination on admission revealed pallor, some dehydration, altered consciousness (GCS 10/15), generalised hypertonia, with no signs of meningeal irritation. There was no jaundice, oedema, lymphadenopathy or respiratory distress. She was hyperthermic (axillary temperature $37.9{ }^{\circ} \mathrm{C}$ ), tachycardic (117 bpm), tachypnoeic (28 bpm), and had normal blood pressure (113/64) and oxygen saturation 4(96-98\%). A full hemogram on admission revealed a normocytic normochromic anaemia (Hb $10.9 \mathrm{~g} / \mathrm{dL}$ ) with reduced haematocrit $(30.7 \%)$ and thrombocytopenia 
(platelets absolute count $12 \times 10^{3} / \mu \mathrm{L}$ ). Random blood sugar was $7.9 \mathrm{mmol} / \mathrm{L}$. Microscopic examination of blood smear was positive for $P$. falciparum (200 parasites $/ \mu \mathrm{L}$ ). Urinalysis and cerebrospinal fluid analysis were normal, and triple serology was negative. On the basis of these clinical findings, the patient was diagnosed with severe malaria with altered consciousness, prostration, and bi-cytopenia. Artesunate $(2.4 \mathrm{mg} / \mathrm{kg} /$ dose $)$ was administered at 0,12 , and $24 \mathrm{hrs}$ then once daily. Ceftriaxone $2 \mathrm{~g}$ twice daily was also administered.

On the second day of admission, the patient had 2 episodes of diarrhoea and was anuric. The renal workup revealing elevated serum creatinine $(664 \mu \mathrm{mol} / \mathrm{L})$ and urea (39 mmol/l), hyponatremia (serum sodium $130 \mathrm{mmol} / \mathrm{L}$ ) and hypochloraemia (serum chloride $91 \mathrm{mmol} / \mathrm{L}$ ). The patient was diagnosed with AKI and admitted to the renal unit for emergency haemodialysis. Blood transfusion was done during haemodialysis. Volume expansion was done and diuretics administered, and the patient put on a renal diet. After 2 dialysis sessions, the level of consciousness had improved (GCS 12/15), but the patient developed periorbital and bilateral pitting pedal oedema and hepatomegaly of 8 $\mathrm{cm}$ below the costal margin. Furosemide $40 \mathrm{mg}$ once daily was administered for three days. Serial renal workup for the patient was as shown in Table 1.

On the ninth day of admission (after $4^{\text {th }}$ haemodialysis session) patient developed diffuse tetanic movement, irritability, confusion and a positive Trousseau's sign. Notably, her blood pressure was also elevated $(164 / 97 \mathrm{mmHg})$. A diagnosis of stage II hypertension and hypocalcaemia with a differential of dialysis disequilibrium syndrome was made. Serum calcium level was found to be low (Total calcium $1.94 \mathrm{mmol} / \mathrm{L}$; corrected calcium $1.5 \mathrm{mmol} / \mathrm{L})$. She was treated with one cycle of $300 \mathrm{mg}$ of calcium gluconate in $5 \%$ dextrose over 2 hours, followed by oral supplementation of calcium (300 mg of elemental calcium daily) for a week. There was significant reduction of tremors after the intravenous treatment, and there was complete resolution within 48 hours of initiating the treatment. Serial calcium levels for the patient were as shown in Table 2.

The blood pressure was adequately controlled with antihypertensives (amlodipine $5 \mathrm{mg}$ OD and enalapril $5 \mathrm{mg} \mathrm{OD}$ ) which were titrated and tapered down to optimize the blood pressure. The patient was discharged from the hospital 4 days later on follow-up oral treatment with $300 \mathrm{mg}$ of elemental calcium daily for three days and amlodipine $5 \mathrm{mg} O D$. She was also advised on renal diet, blood pressure monitoring and follow-up at the renal unit. She was closely followed up after a week, and monthly for 2 months, and was found to have normal kidney functions.

\section{Discussion}

This case report illustrates a manifestation of severe malaria less often seen in autochthonous older children.

Table 1: Serial renal work-up.

\begin{tabular}{|c|c|c|c|}
\hline Day Since Admission & $\begin{array}{l}\text { Creatinine }(\mu \mathrm{mol} / \mathrm{L}) \\
(\text { Lab Normal }=53.93-99.01)\end{array}$ & $\begin{array}{l}\text { Urea }(\mathrm{mmol} / \mathrm{L}) \\
(\text { Lab Normal }=3.5-7.2)\end{array}$ & Electrolytes \\
\hline 2 & 664.42 & 39.0 & $\begin{array}{l}\text { Hyponatremia }(130 \mathrm{mmol} / \mathrm{L}) ; \\
\text { hypochloraemia }(91 \mathrm{mmol} / \mathrm{L})\end{array}$ \\
\hline 3 & 888.91 & 40.7 & Not Available \\
\hline 6 & 665.30 & 18.2 & Hyponatremia (130 mmol/L) \\
\hline 7 & 542.95 & 11.5 & Normal \\
\hline 9 & 597.47 & 11.9 & Hypocalcaemia (1.94 mmol/L) \\
\hline 10 & Not Available & 11.0 & $\begin{array}{l}\text { Hyponatremia (132.3 mmol/L; } \\
\text { Hypochloraemia (97 mmol/L) } \\
\text { Hypocalcaemia (1.98 mmol/L) }\end{array}$ \\
\hline 12 & 577.84 & 14.4 & Normal \\
\hline 13 & 277.49 & 7.2 & Normal \\
\hline 21 & 133.46 & 7.1 & Normal \\
\hline
\end{tabular}

Table 2: Serial calcium levels.

\begin{tabular}{|l|l|l|}
\hline Day Since Admission & $\begin{array}{l}\text { Total Calcium (mmol/L) } \\
\text { (Lab Normal 2.02-2.59) }\end{array}$ & $\begin{array}{l}\text { Estimated Corrected Calcium (mmol/L) } \\
\text { (Lab normal 2.02-2.59) }\end{array}$ \\
\hline 9 & 1.94 & 1.50 \\
\hline 10 & 2.50 & 2.70 \\
\hline 12 & 2.18 & 2.30 \\
\hline 13 & 2.08 & 2.20 \\
\hline
\end{tabular}


The cornerstone of severe malaria treatment is prompt administration of antimalarials, and the provision of appropriate supportive management. Intravenous artesunate is now the first line treatment option for severe $P$. falciparum malaria as recommended by the WHO, and quinine and artemether are the second-line options [5]. Landmark Randomised controlled trials have demonstrated that artesunate reduces mortality in severe malaria by $35 \%$ in adults and $23 \%$ in children, relative to quinine $[6,7]$. We urgently instituted treatment with artesunate upon diagnosis of severe malaria in this patient.

$\mathrm{AKI}$ is one of the most serious complications of severe malaria. The Kidney Disease: Improving Global Outcomes (KDIGO) defines AKI as the rapid deterioration of renal function, characterised by either: 1 ) a reduction in urine output to $<0.5 \mathrm{~mL} / \mathrm{kg} / \mathrm{h}$ for 6 hours, 2) an increase in serum creatinine by at least $0.3 \mathrm{mg} / \mathrm{dL}(26.53 \mu \mathrm{mol} / \mathrm{L})$ within 48 hours, or 3 ) an increase in serum creatinine to at least 1.5 times the baseline within 7 days. Using the KDIGO criteria, recent studies have estimated a high prevalence of AKI in patients with malaria of $20 \%$ to $40 \%$ in adults and up to $59 \%$ in children $[8,9]$. In this case report, the patient met the first two definitions of $A K I$. AKI is an established independent predictor for mortality in children with severe malaria [10].

The aetiopathogenesis of AKI in malaria has not been clearly established, although various pathological processes have been described. Pre-renal AKI may occur as a result of volume loss due to vomiting, diarrhoea and insufficient fluid intake. However, renal injury is also thought to occur as a result parasite sequestration, endothelial dysfunction, immune-mediated damage and oxidative stress [11]. $P$. falciparum infection is characterised by massive intravascular haemolysis of infected erythrocytes and release of heme, which is associated with oxidative damage of renal tubular cells. More so, plasmodium-infected RBC express some parasite proteins on their surface, which enhance the cellular adherence to vascular endothelial cells [11]. The consequent endothelial activation and vascular obstruction likely play a central role in kidney and other end-organ damage.

For patient with malarial AKI, cautious fluid management is essential, as the AKI may not necessarily be due to hypovolemia, and the patients can easily develop fluid overload with pulmonary oedema [12]. In fact, fluid bolus therapy among African children with severe malaria has shown a relative increase in the risk of death of up to 1.59 [13]. The WHO recommends individualised restrictive fluid administration with slow infusion of isotonic crystalloids [14]. Renal replacement therapy has been shown to improve mortality in malaria-associated AKI from about 75\% to about $26 \%$. Considering the rapid progression and multiorgan involvement in malarial AKI, early initiation of renal replacement therapy is recommended [15]. Intermittent haemodyalysis is the preferred option of renal replacement therapy.

Hyponatremia and hyperkalemia are the most common electrolyte abnormalities seen in malarial AKI [16]. Hyponatremia may be as a result of the initial internal dilution and later sodium wasting prior to the oliguric phase of AKI, while hyperkalemia is primarily due to haemolysis [17]. At the time of AKI diagnosis, the patient had hyponatremia, but the potassium levels remained within the normal ranges.

Hypocalcemia in AKI may occur as a result of a reduction in renal coversion of 25 -hydroxyvitamin $D$ to the active 1,25-dihydroxyvitamin D [18]. More so, $P$. falciparum-associated rhabdomyolysis [19] may lead to calcium sequestration into the injured muscle [18]. In patients undergoing haemodialysis, hypocalcemia may be a consequence of low diasylate calcium [20] and sudden reduction in parathyroid hormone concentration [21]. For this patient, hypocalcemia was not diagnosed until when the patient was symptomatic (after the $4^{\text {th }}$ haemodyalysis session) because calcium and phosphate levels were not part of the basic electrolytes panel provided. Since the patient was anuric and had just a few episodes of diarrhea, it was unlikely that calcium was lost externally. Therefore, the hypocalcemia could have been as a result of malarial AKI, haemodialysis or a combination of the two. The standard treatment of acute symptomatic hypocalcemia is intraveous supplementation (with calcium gluconate or calcium chloride) until resolution of symptoms, followed by oral supplementation of calcium, and if warranted, therapy with vitamin D [22]. One cycle of intravenous infusion of calcium, followed by oral supplementation was adequate in correcting the hypocalcemia within 48 hours in this patient. We emphasized on slow infusion of calcium gluconate (over 2 hours) to avoid arrythmia, which is commony associated with rapid infusion.

Hypertension is a common finding in chronic kidney disease (CKD). However, various animal studies $[23,24]$ and studies in children [25] have linked AKI with the development of hypertension acutely, or in the longterm. In a more recent study, the prevalence of hypertenion in patients with AKI was found to be as high as $70 \%$, with dialysis being a predisposing factor for the need for antihypertensive therapy [26]. In this case study, the patient developed hypertension about 7 days after the diagnosis of AKI. AKI has been associated with longterm decline in renal function and development or acceleraion of CKD, which is commonly associated with hypertension [27]. However, the aetiopathology of hypertension immediately following AKI is yet to be fully established [26].

\section{Conclusion}

Severe malaria is a common cause of paediatric 
morbidity and mortality. Acute kidney injury is a common complication of malaria. The prognosis of malarial AKI depends of early diagnosis and initiation of supportive and definitive treatment. Hemodialysis facilitates swift restoration of renal function. It is also important to watch out for complications such as electrolyte abnormalities and hypertension before, during and after hemodyalysis.

\section{References}

1. Snow RW, Sartorius $B$, Kyalo D, Maina J, Amratia $P$, et al. (2017) The prevalence of plasmodium falciparum in subsaharan africa since 1900. Nature 550: 515-518.

2. WHO (2020) World malaria report 2020.

3. Plewes K, Leopold SJ, Kingston HW, Dondorp AM (2019) Malaria: What's new in the management of malaria? Infect Dis Clin North Am 33: 39-60.

4. Das BS (2008) Renal failure in malaria. J Vector Borne Dis 45: 83-97.

5. Noubiap JJ (2014) Shifting from quinine to artesunate as first-line treatment of severe malaria in children and adults: Saving more lives. Journal of infection and public health 7 : 407-412.

6. Dondorp AM, Fanello CI, Hendriksen IC, Gomes E, Seni A, et al. (2010) Artesunate versus quinine in the treatment of severe falciparum malaria in african children (AQUAMAT): An open-label, randomised trial. The Lancet 376: 16471657.

7. Dondorp A, Nosten F, Stepniewska K, Day N, White N (2005) Artesunate versus quinine for treatment of severe falciparum malaria: A randomised trial. Lancet: 366: 717725.

8. Muhamedhussein M, Ghosh S, Khanbhai K, Maganga E, Nagri Z, et al. (2019) Prevalence and factors associated with acute kidney injury among malaria patients in dar es salaam: A cross-sectional study. Malaria research and treatment: 2019.

9. Afolayan FM, Adedoyin OT, Abdulkadir MB, Ibrahim OR, Biliaminu SA, et al. (2020) Acute kidney injuries in children with severe malaria: A comparative study of diagnostic criteria based on serum cystatin $c$ and creatinine levels. Sultan Qaboos Univ Med J 20: e312-e317.

10. Von Seidlein L, Olaosebikan R, Hendriksen IC, Lee SJ, Adedoyin OT, et al. (2012) Predicting the clinical outcome of severe falciparum malaria in african children: Findings from a large randomized trial. Clin Infect Dis 54: 1080-1090.

11. Katsoulis O, Georgiadou A, Cunnington AJ (2021) Immunopathology of acute kidney injury in severe malaria. Front Immunol 12: 651739.

12. Hanson J, Anstey NM, Bihari D, White NJ, Day NP, et al. (2014) The fluid management of adults with severe malaria. Criti Care 18: 642.
13. Maitland K, Kiguli S, Opoka RO, Engoru C, Olupot-Olupot $P$, et al. (2011) Mortality after fluid bolus in african children with severe infection. N Engl J Med 364: 2483-2495.

14. WHO (2015) Global technical strategy for malaria 20162030.

15. Plewes K, Turner GD, Dondorp AM (2018) Pathophysiology, clinical presentation, and treatment of coma and acute kidney injury complicating falciparum malaria. Curr Opin Infect Dis, 31: 69-77.

16. Kamath N, lyengar A (2018) Infections and the kidney: A tale from the tropics. Pediatric Nephrology 33: 1317-1326.

17. Brown DD, Solomon S, Lerner D, Del Rio M (2020) Malaria and acute kidney injury. Pediatr Nephrol 35: 603-608.

18. Palevsky PM (2020) Acute kidney injury: Complications associated with acute kidney injury. Nephrology Hypertension.

19. Mishra SK, Pati SS, Mahanta KC, Mohanty S (2010) Rhabdomyolysis in falciparum malaria-a series of twelve cases (five children and seven adults). Trop Doc 40: 87-88.

20. Ulozas E, Chebrolu SB, Shanaah A, Daoud TM, Leehey DJ, et al. (2004) Symptomatic hypocalcemia due to the inadvertent use of a calcium-free hemodialysate. Artif Organs 28: 229-231.

21. Phelps KR, Mo J, Czerwinskyj C, Mathew RO (2016) Transient hypocalcemia in a dialysis patient with paget's disease and presumed renal cell carcinoma. Journal of Investigative Medicine High Impact Case Reports 4.

22. Schafer AL, Shoback DM (2016) Hypocalcemia: Diagnosis and treatment. Endotext [Internet].

23. Spurgeon-Pechman KR, Donohoe DL, Mattson DL, Lund $\mathrm{H}$, James L, et al. (2007) Recovery from acute renal failure predisposes hypertension and secondary renal disease in response to elevated sodium. Am J Physiol Renal Physiol 293: F269-F278.

24. Pechman KR, De Miguel C, Lund H, Leonard, EC, Basile $\mathrm{DP}$, et al. (2009) Recovery from renal ischemia-reperfusion injury is associated with altered renal hemodynamics, blunted pressure natriuresis, and sodium-sensitive hypertension. Am J Physiol Regul Integr Comp Physiol 297: R1358-R1363.

25. Vivante A, Twig G, Tirosh A, Skorecki K, Calderon-Margalit $R$ (2014) Childhood history of resolved glomerular disease and risk of hypertension during adulthood. JAMA 311: 1155-1157.

26. Dylewska M, Chomicka I, Malyszko J (2019) Hypertension in patients with acute kidney injury. Wiad Lek 72: 21992201.

27. Hsu C-y, Hsu RK, Yang J, Ordonez JD, Zheng S (2016) Elevated BP after AKI. J Am Soc Nephrol 27: 914-923. 